\title{
Development of Learning Devices Commercial Graphic Based Planning Project
}

\author{
Menul Teguh Riyanti ${ }^{1}$
}

\section{Faculty of Art and Design University \\ Trisakti, Indonesia. \\ Email:menulsukarno@yahoo.com \\ Licensed: \\ This work is licensed under a Creative Commons Attribution 4.0 License.}

Keywords:

Model development of instructional Project based learning Majoring study of commercial graphics project.

\begin{abstract}
The purpose of this study was to develop a learning model based Commercial Graphic Design project-based learning approach, was chosen as a strategy in the learning product development research. University students as the target audience of this model are the students of the fifth semester Visual Communications Design Studies Program Faculty of Art and Design University of Trisakti. Dick, Carey, and Carey models of Research and Development ( $R$ and $D)$ are applied to develop this model. The model consists of the systematic phase used to develop products Commercial Graphics. Results of learning products reviewed by expert instructional design, instructional material expert, and instructional media specialist. A series of formative evaluation session - a review and revision process - undertaken in developing this learning products. The results showed that the learning model Commercial Graphics implemented a project-based approach has been improving learning outcomes better than the target - the students of the fifth semester Visual Communications Design Studies Program Faculty of Art and Design University of Trisakti. The results of the research and development of this model in the category of Good. Product effectiveness learning materials can be seen from the test results of students before reading the book knowledge and test results after reading the book. The average value of pre-test result is 64,4, while the result of posttest result is 78,80 The result shows improvement of learning result, test value shows bigger than 17,36 means, and it can be concluded that the learning materials product can improve student learning outcomes. The result of observation from class also shows result of achievement of indicator with answer yes is, 100\%, for opening activity, 98,33\%, for core activity.
\end{abstract}

\section{Introduction}

The course of Commercial Graphic Planning is the main course as a prerequisite for continuing the course of Social Graphic Planning on Visual Communication Design course in the Faculty of Visual Arts and Design of Trisakti University. In fact, the transformation of knowledge in the course of Commercial Graphic Planning, cannot be accepted well. Students feel bored and less interested in attending lectures, and not interested to ask during lectures, this happens because lecturers are less interactive in the delivery of theoretical learning materials and practices, as well as less varied training, also the use of learning materials. So that the provision of analysis and completion of tasks in the form of projects less than the maximum. The fact that in the course of Commercial Graphic Planning is very difficult to get good value, the average value that can be $\mathrm{C}$ and $\mathrm{D}$. The current learning process is still using the lecture method, centered on the lecturer. Lecturer should be able to transform and facilitate the students in the learning process that is not boring by designing and presenting the learning effectively, efficiently and interestingly. Learning process of Project Based Project Graphic Planning, lecturers should be only as facilitators, then deliver the theoretical learning materials as well as provide practical activities for students to achieve learning objectives by prioritizing learning activities through the interaction between students and lecturers. Thus the project-based learning model is expected to facilitate the achievement of student-oriented learning, so that the value of students achieve an optimal value of A. The name of the Visual Communication Design IV course was renamed in 2016 according to the curriculum used, into Commercial Graphic Planning. The course of Commercial Graphic Planning is very specific, namely the concept of establishing the identity of commercial communications, through the media above the line advertising is the marketing of products / services by using on-line media, print and radio while the media below the line advertising promotions conducted at the retail level and New Media Mix is a social media like Facebook, Twitter, Youtube, Instagram become one of the strengths in the 
course of planning commercial graphics, students are able to create a concept of design work that is unthinkable by others but in the course of planning commercial graphics is the stage from base to next stage with material to provide solutions how a company can increase sales by creating innovative design works called out of the box.

\section{Problem Identification}

Based on the results of preliminary studies conducted by researchers through, obeservasi, interviews and questionnaires, it is necessary development of learning models that can be used as an alternative and also as a reference to motivate and improve students' learning ability. The product of the designed and developed learning materials contains; guidebook of learning materials for lecturers and students, materials for general learning materials. In the research and development of this learning model, the researcher involves the lecturer of the subjects of Commercial Graphic Planning as a collaborator to develop a project-based learning model in the commercial graphic planning course at Trisakti University at the Faculty of Visual Arts and Design, especially the Visual Communication Design study program. This research is a research and development based on The Research \& Development ( $R$ \& D) cycle from Borg and Gall for the stages of information collecting data and the development stage of learning materials using Walter, Lou, and James (2009). model development steps. Borg and Gall states Research and development is a process for developing and validating educational products. Research and Development used to design product of project-based project-based Graphic Planning materials at Faculty of Art and Design Trisakti University using Gall, Gall, and Borg (2007) research and development approach. According to him to develop the learning product can be used model design system Dick and Carey.

In its development, Borg and Gall recommend model development products using Dick and Carey's instructional system design models. In the product development recommendation, Walter et al. (2009). have 10 interconnected stages between the components and continuous, the stages are: (1) Identifying the Instructional objectives; (2) Instructional analysis can be performed in parallel in the third stage; (3) analysis of learners; (4) writing instructional objectives; (5) revising instructional; (6) develop assessment instruments; (7) development of instructional strategies; (8) developing and selecting instructional materials; (9) design and carry out formative evaluations; (10) design and construct summative evaluation. This research procedure adapts from two research and development models to have more value in terms of research that will be done through preliminary research. This preliminary study was conducted by conducting literature studies and field research. Library study was conducted to obtain a conceptual model, while field research to obtain the factual model. In the literature study, researchers collect various sources of libraries consisting of reference books related to project-based learning. Assessments are conducted to obtain information on theories and concepts related to project-based learning. Theories and concepts on project-based learning serve as the basis for modeling the model of project-based learning for the students of Commercial Graphic Planning for semester V. Then for field research aims to find out the needs in Commercial Graphic Planning using project-based learning., the researchers distributed questionnaires to lecturers and students of the Commercial Graphic Planning Faculty of Art and Design of Trisakti University. The results of the questionnaire indicate the need for learning tools that can assist lecturers in learning process activities at the Faculty of Art and Design. It is one of the background researchers doing research and development model. Researchers limit the Visual Communication Design Study Program at the Faculty of Visual Arts and Design of Trisakti University. The data in previous research were obtained through several data collection techniques, namely by distributing questionnaires, interviews, and observations. To obtain academic validity and expertise of questionnaires collection tools, interview sheets and observation sheets were reviewed by experts in their respective fields. Data collection tools in the form of questionnaires, questionnaires, interview sheets, and observation sheets are reviewed by experts to obtain validity and academic recognition and expertise. Experts reviewing data collection tools are promoters and co-promoters. From the point of view, the data collection tool is reviewed by linguists. Meanwhile, in terms of the substance of education technology and media data collection tool by media experts. Once eligible and eligible, the data collection tool can be used in research.

\section{Theoretical Review}

\subsection{Learning Model Development Concepts}

Learning design model is a description of systematic design process about the development of learning both about the process and learning materials in accordance with the needs in the effort to achieve learning objectives. The model also means as a graphical display, a regular or systematic work procedure, containing descriptive or explanatory ideas along with suggestions, according to Paul and Don (2012). Another opinion reveals that the model of instructional design shows the structure of work and meaning for components and workflow that can be followed by the designer in translating it into a learning. The model is a conceptual analogue used to suggest how it should continue the empirical research of a problem. Learning model is a plan or a pattern used as a guide in planning learning in class, Ngalimun and Ahmad (2016). 


\subsection{Concepts of Project-Based Learning (Bookallil, Chalmers, \& Bell, 2005)}

Project-based learning is a learning model that involves a project in the learning process. Projects undertaken by students can be either individual or group projects and are carried out within a certain time in a collaborative manner, an effort to produce a product, and the results are then displayed or presented. Project implementation is collaborative and innovative, unique, focusing on solving problems related to student life. Project-based learning is part of instructional (instructional) method that centers on the learner or student. The definition is in line with the description presented by Bell, which is as follows;

a. Project Based Learning is full curriculum and standards based.

The project-based learning model is a learning model that requires standardized content in the curriculum. Through project-based learning, the inquiry process begins with raising a guiding question and guiding students in a collaborative project that integrates the various subjects (curriculum) in the curriculum.

b. Project Based Learning asks a question or poses a problem that each student can answer.

Project-based learning is a learning model that requires teachers and / or students to develop a guiding question. Given that each student has a different learning style, project-based learning provides an opportunity for students to explore content by means of various means that are meaningful to themselves, and conduct collaborative experiments. This allows each student to finally be able to answer the guide questions.

c. Project Based Learning asks students to investigate issues and topics addressing real-world problems while integrating subjects across the curriculum.

Project-based learning is a learning model that requires students to create "bridges" that connect between different material subjects. In addition, project-based learning is an in-depth investigation of a real-world topic.

d. Project Based Learning is a model that fosters abstract, intellectual tasks to explore complex issues.

Project-based learning is a learning model that takes into account students' understanding of exploration, assessment, interpretation and synthesis of information through meaningful means. Project-based learning is also a learning model involving the centralization of meaningful questions and problems, problem solving, decision-making, the search process of multiple sources, the provision of opportunities for members to work in collaboration, and closing with real-world product presentations.

The application of this project-based learning model has several reasons, namely:

1) Produce the concept design and application of design products commercially (selling point), and socialized to the general public.

2) In the conventional education process leading to modernization, learning is the management and utilization of knowledge development that involves the development of thought processes.

3) The group learning process (Cooperative Learning) which is interconnected and supportive, open the creativity, because students implement and apply their design concept in accordance with the assistance of the lecturer the course.

Design of Research and Development of Project-Based Commercial Graphic Planning Learning Model.

The instructional design model is used as a guide in research and development of project-based subject materials. Project-based Graphic Planning is based on Borg \& Gall's research and development model and (Walter et al., 2009) instructional design model.

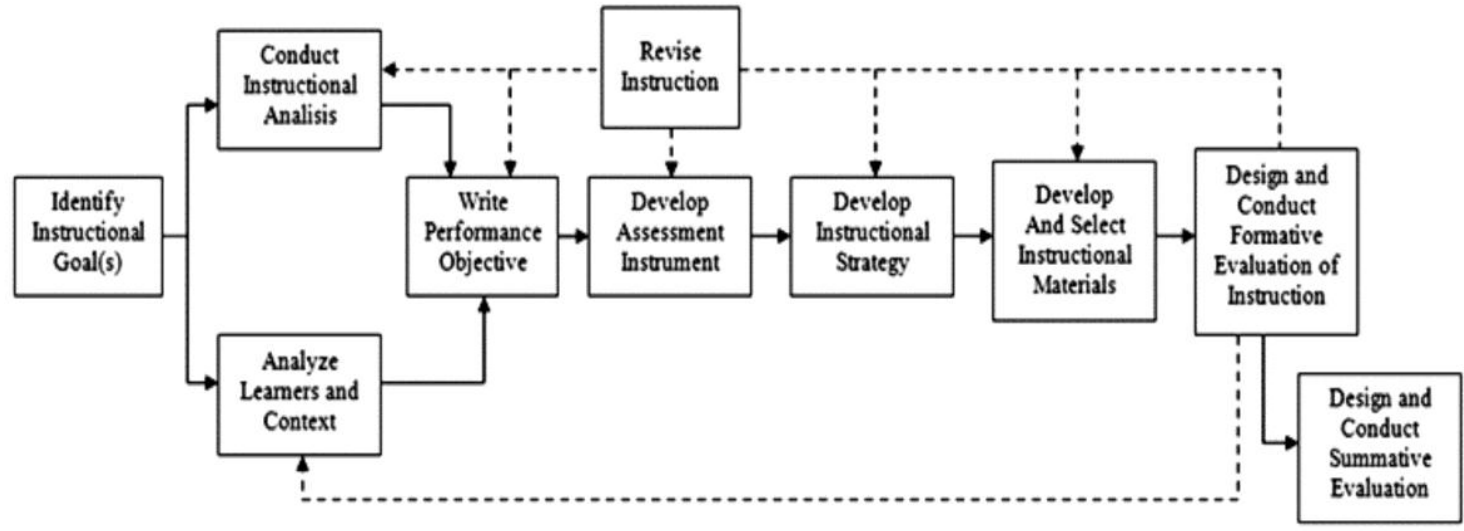

Figure-1. Walter et al. (2009).

The steps of developing the learning model using steps from Walter et al. (2009) consists of 10 stages: 1. Identify and set general learning objectives

2. Analyze learning characteristics 
3. Analyze student characteristics and context

4. Write down the learning objectives

5. Revise Instructional

6. Develop assessment instruments

7. Develop learning strategies

8. Selecting and developing learning materials and materials

9. Design and carry out formative evaluation

10. Develop and Implement summative evaluation

In the research and development of learning model of Project-Based Commercial Graphic Planning, researchers only perform phase 1 to stage 9 Dick and Carey is formative evaluation. For stage 10. Summative evaluation is not implemented due to time and cost constraints. The stage 1 and stage 9 Dick and Carey consists of four steps, namely;

1) Validation of instructional materials designed, reviewed by expert learning materials on Project-Based Commercial Graphic Planning, Project-Based Project-Based Graphic Design Experts, Project Planning-based Graphic Media Learning Specialists. Validation by the experts mentioned above to obtain the feasibility of learning products from input and suggestions.

2) This one-to-one learner is conducted to get initial feedback about the product. Individual trials were conducted for 1-3 students. After the individual testing, through one student test, then the results obtained then the researchers revise the product or design based on input from the assessment or validation test of experts.

3) Small group trial. This trial involves students consisting of 1-15 students. The results of this small group trial were obtained to undertake the feasibility and revision of learning materials products.

4) field trial. Field trials involving students from 1 to 25 people in the classroom. The results of this field trials are used to see the effectiveness of learning product materials. Before looking at the effectiveness of learning products, researchers conduct and implement pre-test and post-test, to see the increase in student learning outcomes.

\section{Research Results and Discussion}

This explains the discussion of expert review and field test results. The discussion of learning model development outcomes is presented in three sections, namely (1) the importance of model development in the learning process, (2) development model design, (3) model development and educational technology, (4) model development and improvement of competence, and (5) ) product advantages and disadvantages.

The following describes the results of validity and Expert Test on the model of development of projectbased Commercial Graphic Planning.

\section{Feasibility of the Learning Material Expert}

Based on the result of the evaluation of the above material, the average score for the learning material 1 is $78.3 \%$, while the 2 subject matter experts with the result of the average score of $76 \%$ thus the development of the material is categorized as effective or good. This value is certainly influenced by each diverse indicators. The scoring interval using likert scale.

\section{Feasibility of the Learning Design Expert}

Validation of media experts includes elements of model graduation. Indicators of elements of grafica consist of (1) Formulation of Instructional Objectives, (2) Organizing Strategies, (3) Strategies for Presentation of Materials, (4) Instructional Management Strategies. The results of the validation of the design expert of the learning can be described as follows for the average media score of score 4 so that for the media almost as a whole with good results, for more details can be seen in the following figure:

\section{Model Feasibility by the Learning Media Expert}

Validation of media experts includes elements of model graduation. Indicators of elements of kegrafikaan consist of (1) Size of the Learning Handbook, (2) Cover Design, (3) Design Contents of the Learning Handbook. Expert media validation results can be described as follows for the average media score of score 4 so that for the media almost as good overall, the data can be seen in the following figure:

\section{One to one trial}

One to one learner test was conducted on 3 (three) students of 5th semester 1 student representing achievement with less ability, 1 student representing moderate achievement, and 1 student representing high achievement. Student achievement indicator is seen from the student's Grade Point Average (GPA). 
a. Aspects of Clarity of Learning Materials

Indicator of the preparation of learning materials by 3 students as subjects gave researchers a score. Students assess the material from the guidebook of Learning Guidebook is in accordance with the needs of students by obtaining the average score of 4.00 .

\section{b. Design Aspects}

Aspects of the design, among others, concerning the choice of color blend used in the model of learning model of Commercial Graphic Planning. According to three students the color blend used between the average use of the score. According to the three guys, the color guides used were very interesting with the average score of 4.50. In this case the layout of this material.

\section{Small Group Trial}

After getting input from one to one, revision is made, the revision result is done by small group trial and data below;

a. The clarity aspect of student material as the subject of research gives score the student assess the material of instructional manual of project based Commercial Graphic Planning according to student requirement with got average score 3,66. The material has been able to motivate the students to be actively involved in the learning process and can open students thinking horizons by obtaining the average score of 3.66. In addition, the questions on the questions presented in the project-based project-oriented Graphic Project Planning guide book are easy to understand with material clarity and are well worth applying.

\section{b. Design aspect}

For student aspect aspect as research subject give where student assess from visual appearance and illustration in Project-based Commercial Graphic Planning manual. Choice of color guides used with the average of 3.66. Views of tables and graphs by 8 students already understand with a mean of 3.66. The cover and title designs have been able to describe the contents of the Project-based Commercial Graphic Planning manual with an average of 3.66. The physical appearance of the book has been interesting by obtaining the average of 3,66 perfect categories (good). Illustrations and drawings can help students to master the material of Commercial Graphic Planning lesson manual by taking score 3.66. Overall for the aspect of display and illustration and layout is equivalent to the average of 3.66 is eligible for publication.

\section{Model Effectiveness}

The purpose of the field trial test is to apply the product of a project-based Commercial developer in accordance with the actual circumstances. Field trial is done in Visual Communication Design Study Program and the number of students in the course of Commercial Graphic Planning are 25 students. The conclusion of class observation is done, that the learning activity of course of Commercial Graphic Planning is held 5 times meeting. One meeting is 6 x 110 minutes. Most learning activities $(86,67)$ can be done well.

\section{Evaluation of Student Learning Results}

Evaluation of learning outcomes done during field trial test, namely assessment of pres-test, post test, discussion, preparation of paper reports, presentations and formative tests in each chapter. a. Pre-test and Post-test.

The effectiveness of the model by comparing the students' learning outcomes as measured by the Pre-test at the beginning of the learning process and the post-test at the end of the learning process. Pre-test in the form of a written test, carried out before the students undergo the process of learning with the model developed. While Post-test written test is implemented after the students undergo the learning process using a model that is designed. The questions given in the pre-test and post-test are the same, totaling 10 questions with the weight of the value of 1 matter $=10$ points. Results obtained 78.80. The average pre test is 61.44 , while the post test is 78.80 . These results show an increase in test score of 17.36 This means, it can be concluded that the product can improve learning outcomes.

\section{Conclusion}

Based on the formulation of problems and research objectives and discussion of the results of research that has been put forward in the previous chapters, then from this research and development can be concluded that:

Product effectiveness learning materials can be seen from the test results of students before reading the book knowledge and test results after reading the book. The average value of pre-test result is 64,4 , while the result of posttest result is 78,80 The result shows improvement of learning result, test value shows bigger than 17,36 means, and it can be concluded that the learning materials product can improve student learning outcomes. In addition to the results of knowledge tests, the results of this large group trial is obtained from the score assessment of the presentation activities and activities of students in making the design concept in accordance with the assignment in the book of learning materials, the scoring score shows above the number 
3, meaning can be said in either category. Students can be seen in their entirety, have achieved the competence as set and expected, the product of this learning material can be said feasible and effective. The result of observation from class also shows result of achievement of indicator with answer yes is, $100 \%$, for opening activity, 98,33\%, for core activity.

\section{Implications}

Based on the results of research and development of learning materials products and conclusions that have been described, then the model of learning through product learning materials courses Planing Grafis commercial reports Visual Communication Design study program is expected, that the class is used as a trial can be used as a reference for learning models for other classes.

1. Learning model through Product development of learning materials in the form of project-based learning model is a flexible product use. And does not depend on the particular curriculum that is applicable in the world of education, especially in the Visual Communication Design study program in Indonesia in particular. Therefore, even if there is a curriculum change policy, this learning model can still be used. In principle, the project-based learning model is a student-centered learning model, in assisting and developing high-order thinking skills, to develop project-based and contextual learning. The target of competence is the competency of knowledge, skill, and attitude. Understanding of the project-based curriculum refers to the Indonesian National Qualification framework that needs to be given to students in the learning process.

2. Implementation of project-based learning model requires learning media and props appropriate with classroom conditions, so that learning is more meaningful and interactive between students and students. Therefore, it is necessary to understand the various sources of learning so that students can determine learning media and visual aids by managing and utilizing the learning environment, from facilities and infrastructure that have been facilitated by the Faculty and Visual Communication design study program.

3. The subject-based course of the Project-Based Graphic Project Planning will be maximally used, if the student has a good understanding of project-based learning. Therefore, it needs to be supported by conducting training for students in an effort to improve their skills and competence, for example by holding training and assistance that is true and in accordance with the competencies in the set. Armed with high student passion and high curiosity. With regard to student-centered, student-centered learning, lecturers find it easier to adapt to project-based learning models.

\section{Suggestion}

Based on the focus of the problem, the results of research, and the conclusions of research development of project-based learning model, it should be submitted some suggestions as follows:

1. To the lecturer, in applying the learning process using this learning model requires the process and time to be mastered properly. Lecturers need to continuously try to use the learning model of the development of this research, to find and improve the weaknesses if felt there are still shortcomings.

2. For the organizers in this case, Visual Communication Design Studies Program, especially in the application of learning models can be developed through speech; (1) socialisasi dequately to all lecturers about the learning model that will be used in the application of the learning process. (2) apply and apply this learning model, as part of instructional design that should be done by lecturer into syllabus or RPP form; and (3) organize training plays create lesson design for lecturer of Project-based Commercial Graphic Planning at prodi level, given the background education lecturers Subject Planning Graphics Commercial-based projects mostly come from non-education.

3. For researchers, the results of this research and development, can be used as the basis of reference models and learning methods that will be used in further research to be tested in a broader scale. Efforts that must be done by the researchers of course also based on the mastery of the learning stages by lecturers and students

\section{References}

Bookallil, M., Chalmers, E., \& Bell, A. (2005). Challenges in preventing pyelonephritis in pregnant women in Indigenous communities. Rural and remote health, 5(3), Article No. 395.

Gall, M. D., Gall, J. P., \& Borg, W. R. (2007). Educational research: an introduction (8. utg.): Boston: Pearson/Allyn and Bacon.

Ngalimun, M. F., \& Ahmad, S. (2016). Models and learning strategies (pp. 24): Penerbit Aswaja Pressindo, cetakan.

Paul, E., \& Don, K. (2012). Models and learning strategies. Penerjemah Satrio Wahono, Pearson Education, Inc.500 1 Boylston Street, Boston, MA, 02116 . PT Indeks tahun 2012 Kembangan Utara, Jakarta Barat.

Walter, D., Lou, C., \& James, O. C. (2009). Systematic design of instructional (7th ed., pp. 164-165). Boston: Pearson. 